\section{Sizing it up}

\section{John Gallop}

Measurement Science and Technology. Honorary editor P. A. Payne. IOP. 12/yr. UK $£ 245$, elsewhere $\$ 490$.

NOWADAYS only a few new journals buck the general trend towards greater and greater specialization. That Measurement Science and Technology is one of these is less surprising when one appreciates that it is not an entirely new journal but something of an Institute of Physics reincarnation, having begun life under the title of Journal of Scientific Instrument and appearing more recently as Journal of Physics E.

The editors solicit papers or short notes describing new measurement methods, devices or instrumentation across the whole range of physics, chemistry and life sciences. In addition to research papers, a regular section of shorter design notes is included in every issue, as well as occasional review papers on topics of wider interest (for example, optical aperture synthesis), conference reports, book reviews and a short essay section, in which individuals can air their views on topics having a possibly tenuous relationship with measurement science. I suspect that the aim of the editors is to broaden the scope of Measurement Science and Technology so that it approaches, admittedly only within an instrumentation horizon, the treatment by prestigious multidisciplinary research and news journals such as Nature and Science.

The new sections form a relatively small part of the journal. Former readers of Journal of Physics $E$ will still find much that is familiar: stacks of papers describing novel forms of transducers to measure displacement, temperature, magnetic fields and fluid velocity, but many others which are frankly esoteric. Thus the paper on page 1 of volume 1 in January 1990 was entitled 'An accelerated life-test for bicycle freewheels' and dealt with a test rig for evaluating bicycle components under realistic conditions. Papers tend to be more practical than theoretical. This is a journal that tells its readers how to do experiments, rather than proposing what might be done or even reporting the results of what has been done. From the issues published so far I would estimate that the number of contributions from chemistry and the life sciences are running a very poor second and third to physics. This is scarcely surprising in view of the publishers and the readership of the precursor journals, but it will be interesting to see if the editorial board can translate desire for general coverage into reality.

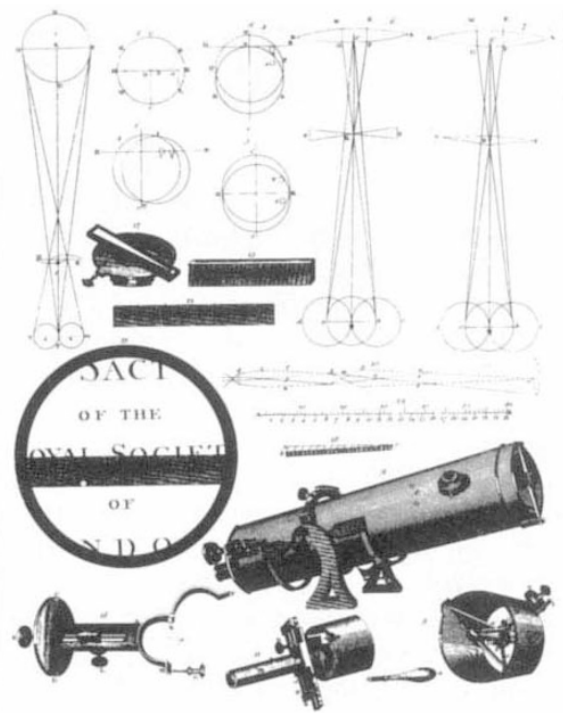

点 out being surprised by something of unexpected relevance or interest to their own work.

Browsing through an issue is perhaps the only way to allow such interdisciplinary seeds to take root. No combination of keywords and on-line databases seems able to produce such cross-fertilization. On the other hand, do today's overworked scientists have time to browse through monthly journals of this size in the hope of coming by chance on a paper that can provide the crucial piece of information they have been needing for months? Surely this is the dilemma that the editors hope to resolve by adding editorial and review material; browsing then allows the acquisition of both broader and narrower knowledge, so that the time allotted to reading the journal will therefore have been more effectively spent.

Already the range of topics covered is great and the originality of many contributions high. I defy any experimental physicist to look through an issue with-

\section{Knowledge bank}

\author{
B. $W u$
}

Journal of Intelligent Manufacturing. Editor-in-chief Andrew Kusiak. Chapman and Hall. 6/yr. Europe 1120, US and Canada $\$ 215$, elsewhere $£ 130$ (institutional); Europe $£ 45$, US and Canada $\$ 80$, elsewhere $£ 45$ (personal).

ONE cannot overstate the importance of manufacturing in an industrialized country, for it is mainly through this activity that the nation's real wealth is created. Today, everyone either is directly involved with manufacturing industry or benefits from its products. Therefore it is vital continuously to improve manufacturing performance. Both the means of manufacturing and the structures of manufacturing systems, as well as the environment within which they operate, have recently radically changed.

So far there have been three stages of industrial development: the neolithic revolution (the age of craftsmanship); the industrial revolution (the age of mechanization); and the new industrial revolution (the age of information and automation). The manufacturing industry is now in the midst of the third of these, the technological revolution, which is characterized by the increasing use of computers for both information processing and automatic control. Whereas the first two stages of industrial development related to hardware (tools and machines) to increase the physical abilities of man, the latest revolution in manufacturing puts more emphasis on information and control to heighten his mental capabili-
John Gallop is in the National Physical Laboratory, Queens Road, Teddington,

ties. This shift is reflected by the publication of this new journal.

The term "intelligent manufacturing" refers to the use of artificial intelligence to improve the effectiveness of manufacturing, including, for example, product design, process design, systems design, strategy development and management operations. Many papers on the subject have already appeared in several journals related to advanced manufacturing technology. As the number of research projects and practical applications increases, the size of published literature in the field has grown quickly. With well-focused and defined objectives, this new journal provides a welcome, encompassing source of much needed information for both academics and professionals involved in intelligent manufacturing.

The journal puts much emphasis on the value of real applications - all of

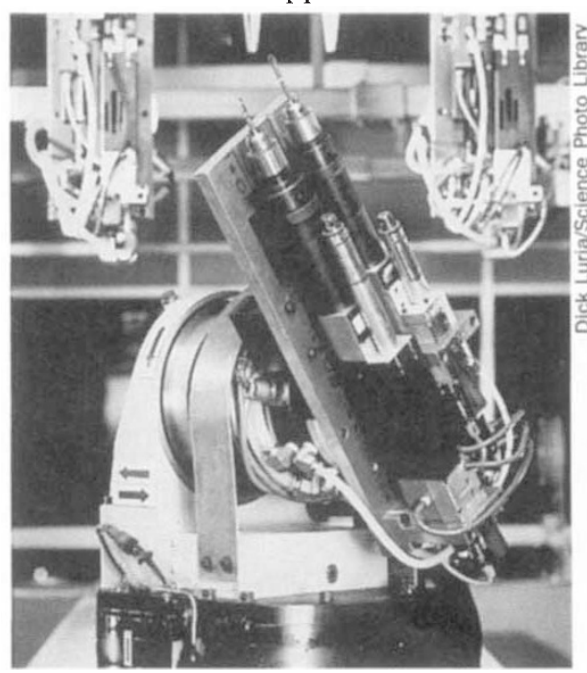

Arm of an industrial robot that drills and deburrs holes. Middlesex TW11 OLW, UK. 